\title{
Alleviation of heat stress in broiler chicken using turmeric (Curcuma longa) - a short review
}

\author{
Sugiharto Sugiharto iD
}

S Sugiharto (Corresponding author)

Department of Animal Science, Faculty of Animal and Agricultural Sciences, Diponegoro University, Tembalang Campus, Semarang, Central Java Province, 50275, Indonesia. email: sgh_undip@yahoo.co.id

Received: May 17, 2020 • Accepted: June 03, 2020 • Published Online: June 16, 2020

\begin{abstract}
Heat stress is one of the most crucial issues in broiler production, particularly in tropical regions. Thermal stress may pose several problems related to growth, feed intake, nutrient utilization, physiological condition, immune function, intestinal ecology, and morphology as well as the antioxidant system in the body of chickens. Turmeric (Curcuma longa) is rich in curcumin, which can serve as an antioxidant. Being part of the nutritional interventions, treatment using turmeric has been documented to alleviate the negative impact of heat stress on broiler chickens, in terms of production, physiology, immunology, and antioxidant status of broilers. The present review elucidates the alleviation of heat stress in broiler chicken using turmeric based on the most recent literature.
\end{abstract}

Keywords: broilers, curcumin, health, thermal stress

\section{Introduction}

Heat stress has been an important factor that should greatly be considered in broiler production particularly in tropical regions (Sugiharto et al 2017a). The retarded growth rate, increased disease outbreaks, and mortality is amongst the problems related to heat stress in broiler production (Sugiharto et al 2017b). The recent increase in global temperature due to climate change seems to further exacerbate the thermal effect on broiler production. Other than establishing the expensive thermal-controlled housing facilities, nutritional intervention such as dietary administration of turmeric has been practiced to alleviate the deleterious effect of heat stress on broiler production. Turmeric (Curcuma longa) belongs to the ginger family and has long been known to be rich in curcumin, which is effective in ameliorating oxidative stress both in humans and animals (Hewlings and Kalman 2017). In vivo studies showed that turmeric treatment could restore the impaired growth performance, physiological alteration, weakened immune system and disrupted antioxidant system in heatstressed broilers (Akhavan-Salamat and Ghasemi 2016;
Sadeghi and Moghaddam 2018), and therefore could reduce or substitute the role of synthetic antioxidants that have recently been legislatively restricted (Sugiharto et al 2019). The ameliorating effect of and the mechanisms through which turmeric acts on heat-stressed broilers are critically discussed based on the most recent literature in the present review.

\section{Heat stress in broiler chicken}

Heat stress is a condition wherein animals are not capable of getting rid of excess heat in their bodies causing an increase in body temperature. Heat stress can occur when the heat load is greater than the animal's capacity to release the excess heat from the body. Thermal stress has been reported to cause several detrimental effects on broilers, including retarded growth rate, reduced feed intake, physiologic changes, gut microbial upset, compromised immune responses, and oxidative damage (Sugiharto et al 2017b). In agreement, Santos et al (2019) have recently reported that thermal stress caused mucosal and villus damage of the small intestine, which can be attributed to the compromised digestive and absorptive functions of chickens. The latter authors also revealed that heat stress modulated oxidative stress and inflammation as well as impaired intestinal integrity and nutrient transport of broilers. Likewise, Shi et al (2019) documented that heat stress-induced dysbiosis or altered composition of gut microbiota (both abundance and diversity of species). The latter condition consequently increased intestinal permeability and immune and metabolic dysfunctions. Concerning the immune defense of birds, Ohtsu et al (2015) previously reported that heat stress disturbed the immune system of broilers by modulating the gene expression of splenic cytokines (interleukin [IL]-4, interferon [IFN]- $\gamma$, and IL-12) and inducing spleen involution. Likewise, exposing birds to high environmental temperatures may implicate in the decreased numbers of lymphocytes and monocytes in the blood. Heat stress also reduced the number 
of $\mathrm{CD}^{+}$and $\mathrm{CD}^{+}$cells of broilers (Xu et al 2018). Moreover, Olfati et al (2018) exhibited that heat stress decreased antibody titer toward sheep red blood cells (SRBC), lymphocyte count and lymphoid organs weights, and increased heterophil to lymphocyte ratio of broilers. Further, the concentrations of heat shock protein-70 (HSP70) and corticosterone in the serum of broilers were increased by heat stress (Olfati et al 2018; Shi et al 2019). In respect particularly to corticosterone, the rise in corticosterone levels may implicate in the impairment of intestinal ecology, morphology, and absorptive functions of broilers (Hu and Guo 2008). The elevated concentration of corticosterone may also negatively modulated metabolism and systemic immune response of broilers (Zaytsoff et al 2019). Moreover, heat stress has been reported to induce organ dysfunctions in broiler chickens. Huang et al (2018) noticed that acute thermal stress increased the levels of some blood biochemical parameters such as blood urea nitrogen (BUN), creatinine, alanine aminotransferase (ALT) and creatine kinase that may indicate the damage of vital organs such as kidney and liver.

To alleviate the deleterious effect of heat stress, several attempts have been executed, one of which is through dietary intervention. Administration of chemical-based or synthetic antioxidants have traditionally been practiced in broilers raised under high thermal conditions. Such an application may, however, be legislatively restricted as the excessive use of synthetic antioxidants may induce carcinogenic and mutagenic effects on humans as broiler consumers (Sugiharto et al 2019). For food safety reasons, there is now therefore a trend to use natural-based antioxidants for ameliorating the thermal stress impacts on broilers. Herbs are among the natural-based antioxidants that have recently been used to deal with heat-stressed broilers (Bagban et al 2016; Sadeghi and Moghaddam 2018).

\section{Turmeric as a source of antioxidant}

Turmeric is an herbaceous rhizomatous plant (Curcuma longa) belonging to the ginger family. Aside from being a cooking spice, turmeric has also been exploited as a feed additive in broiler production. We reported formerly that turmeric extract was able to improve the digestive process and physiological conditions of broiler chickens (Sugiharto et al 2011). Administration of decocted turmeric through drinking water was also reported to improve immune functions and stress responses of broilers (Isroli et al 2017). Turmeric has long been known as a source of curcumin, which has health properties. Curcumin is a natural polyphenol that has widely been known to ameliorate oxidative stress both in humans and animals. Hewlings and Kalman (2017) pointed out that curcumin is capable of scavenging free radicals (such as reactive oxygen species [ROS] and reactive nitrogen species [RNS]), activating glutathione (GSH), catalase and superoxide dismutase (SOD) in neutralizing free radicals and also inhibiting ROS-generating enzymes for instances lipoxygenase/cyclooxygenase and xanthine hydrogenase/oxidase. Chemically, curcumin has a unique structure that is usually attributed to its antioxidant property. Curcumin has carbon-carbon double bonds, $\beta$-diketo group, and phenyl rings containing hydroxyl and methoxy substituents (Boroumand et al 2018). This structure allows curcumin to donate $\mathrm{H}$-atom (from phenolic groups) to neutralize free radicals. In addition to curcumin (which is the primary polyphenols), turmeric powder also contains dimethoxycurcumin and bis- dimethoxycurcumin, 2,5xylenol (Brewer 2011), flavonoids, tannins, and ascorbic acid (Tanvir et al 2017) that can also exhibit neutralizing activity towards free radicals.

In Asian countries, there are several species and varieties of turmeric, which naturally possess different chemical features and biological activities (Akter et al 2019). In agreement with the latter authors, a study in Bangladesh by Tanvir et al (2018) also reported that different turmeric varieties may show different contents of polyphenols, flavonoids, ascorbic acids, and tannins. The different varieties of turmeric may also show different 2,2-diphenyl-1-picrylhydrazyl-hydrate (DPPH) free radical-scavenging activities and ferric reducing antioxidant power (FRAP) values. Owing to these facts, it is, therefore, necessary to be more selective in using turmeric as a source of antioxidants as different varieties may exert different antioxidative effects and therapeutic advantages on broilers.

\section{Effect of turmeric on productive performance of heat- stressed broilers}

Turmeric has recently been exploited to ameliorate the impaired growth performance in broilers exposed to thermal stress (Table 1). It appeared that turmeric was capable of improving nutrient digestibility and hence nutrient utilization by the chicks raised under high thermal condition (El-Maaty et al 2014). Formerly, Namagirilakshmi et al (2010) reported that turmeric powder improved the intestinal ecology and morphology by increasing the number of Lactobacillus and intestinal villi height of broiler chickens. In line with this, Rajput et al (2013) also revealed that feeding curcumin increased villus height, villus height to crypt depth ratio, and the absorptive area of villus of the small intestine of broilers. Taken together, the improving capacity of turmeric on gut ecology and morphology can, therefore, offset the decreased villus height and villus height to crypt depth ratio by heat stress (He et al 2018). Turmeric treatment has also been noticed to increase the weight of the pancreas and length of bile duct epithelial fold and thereby improved the digestive process of broilers (Namagirilakshmi et al 2010). One of the reasons for which heat stress attenuates the growth 
performance is that heat stress impaired the appetite resulting in reduced feed intake of broilers (He et al 2018). Dietary inclusion of turmeric powder has been reported to increase feed intake in broilers during heat stress (Akhavan-Salamat and Ghasemi 2016; Bagban et al 2016). In this case, the appetite stimulant and stomachic and carminative properties of turmeric (Chakraborty et al 2011) seem to account for the increased feed consumption in heat-stressed broiler chickens. Heat stress has been associated with reduced erythrocytes and hemoglobin concentrations in blood (Xu et al 2018). The decreased levels of these blood components can detrimentally affect the growth performance given that erythrocytes and hemoglobin are crucial in transporting and supplying oxygens for cellular respiration. Dietary supplementation of turmeric extract has been reported to increase the concentration of hemoglobin of broilers in the study of Sugiharto et al (2011). The latter author further suggested that the increased hemoglobin value was associated with the increased metabolic rate, and may, therefore, counter the retarded growth rate in heat-stressed broilers. In the previous study, we also reported that the administration of turmeric extract improved stress response in broilers as indicated by the lowered heterophil to lymphocyte (H/L) ratio (Sugiharto et al 2011). Considering that heat stress may enhance the energy expenditure for maintenances rather than for production, the improved stress response with feeding turmeric may therefore partially save the energy for growth in heat-stressed broilers. Thermal stress has been attributed to the attenuated activity of thyroid hormones (triiodothyronine $\left[\mathrm{T}_{3}\right]$ and thyroxine $\left[\mathrm{T}_{4}\right]$ ) and thereby lower metabolic rate and energy production (Sugiharto et al 2017b). Given that curcumin may elevate plasma concentrations of thyroid hormones (Xie et al 2019), feeding turmeric may, therefore, compensate for the reduced activity of thyroid hormones due to heat stress. Moreover, the potentials of turmeric in improving the immune and oxidative system (Swathi et al 2016; Sadeghi and Moghaddam 2018) and thus health are most also likely to save the energy for broiler growth during heat stress.

Table 1 Effect of turmeric on performances of heat-stressed broilers.

\begin{tabular}{ll}
\hline References & Findings \\
\hline Akhavan-Salamat and Ghasemi (2016) & $\begin{array}{l}\text { Turmeric rhizome powder partially restored the decreased body weight gain, } \\
\text { feed intake and mortality of heat-stressed broilers }\end{array}$ \\
Bagban et al (2016) & $\begin{array}{l}\text { Turmeric powder ( } 0.5 \% \text { of diets) increased body weight gain and feed intake of } \\
\text { broilers exposed to thermal stress }\end{array}$ \\
El-Maaty et al (2014) & $\begin{array}{l}\text { Turmeric powder ( } 0.5 \mathrm{~g} / \mathrm{kg} \text { diets) improved final body weight, feed conversion } \\
\text { ratio (FCR) and digestibility of crude protein and ether extract of broilers } \\
\text { exposed to heat stress }\end{array}$ \\
Turmeric powder (0.5\% of diets) increased average daily gain, feed intake, and \\
decreased FCR of broiler exposed to heat stress
\end{tabular}

\section{Effect of turmeric on physiological conditions of heat- stressed broilers}

Raising broiler chickens under high thermal conditions is associated with physiological alterations, which may in turn lead to pathophysiological conditions (Sugiharto et al 2017b). Dietary administration of turmeric has been reported to ameliorate the physiological changes in broiler chickens raised under heat stress conditions (Table 2). The increased concentration of corticosterone is commonly found in the serum of broilers experiencing heat stress (Olfati et al 2018; Shi et al 2019). Considering the catabolic activity of this stress hormone, the increased level of serum corticosterone in broilers during heat stress may implicate in muscle protein break down ( $\mathrm{Xu}$ et al 2018) and diversion of energy from muscle biosynthesis to maintenance (Zaytsoff et al 2019). Feeding turmeric has been noticed to alleviate the increased corticosterone in broilers due to heat stress (Swathi et al 2016). Formerly, Amr et al (2017) reported the efficacy of turmeric powder in restoring the detrimental effect of corticosterone administration on the physiological conditions of broilers. Turmeric is rich in curcumin, which has recently been reported to alleviate the increased corticosterone concentration in broiler chickens (Zhang et al 2019). The latter investigators suggested that the strong antioxidant (anti-stress activity) and hepato-protective capacities of curcumin were attributed to the alleviating effect of curcumin (turmeric) on the increased stress hormone levels due to heat stress. Thermal stress condition has been associated with the reduced thyroid hormones activity and hence reduced energy supply for growth (Sugiharto et al 2017b). Indeed, Zeinali et al (2011) and Sadeghi and Moghaddam (2018) documented that turmeric powder could restore the activities of triiodothyronine and thyroxine in heat-stressed broilers. This may consequently correct the compromised growth rate in broilers due to heat stress. It seems that curcumin in turmeric acted a significant role in stimulating the biosynthetic activity 
of the thyroid gland (Papież et al 2008). In line with the previous study, Rajput et al (2013) and Xie et al (2019) also reported that curcumin was able to increase the activity of thyroid hormones in broilers.

During stress conditions, such as heat stress, the increased level of corticosterone usually implicate increased muscle protein catabolism and thus elevated levels of uric acid and creatinine in the circulation of broilers (Liu et al 2016). Feeding turmeric powder was able to lower the plasma concentrations of uric acid and creatinine in heat-stressed broilers as reported by El-Maaty et al (2014) and Bagban et al (2016). It was possible that the reduced concentration of corticosterone due to turmeric administration (Swathi et al 2016) may lower the catabolic activity of muscle protein and thus reduce the content of uric acid and creatinine in the circulation. Turmeric may also improve feed intake and digestibility (El-Maaty et al 2014; Sadeghi and Moghaddam 2018) and thereby improve the energy supply for the chickens during thermal stress. The latter condition eventually reduced muscle protein catabolism and hence uric acid and creatinine in the plasma of heat-stress chicks. Literature documented that turmeric could ameliorate the negative effect of heat stress on lipid and cholesterol profile in broilers (Hosseini-Vashan et al
2012). It seemed that curcumin in turmeric helped the liver in taking low-density lipoprotein (LDL) out of circulation. Curcumin also increased the production of bile salts by the liver to carry the excess LDL out of the body of chicks (Adegoke et al 2018). In line with this, Xie et al (2019) reported that curcumin may modulate the expression of genes related to lipogenesis and lipolysis resulting in reduced LDL and triglycerides concentrations in the plasma and liver of broilers. Organ dysfunction has been attributed to heat stress in broilers (Huang et al 2018). Interestingly, turmeric may ameliorate such tissue damage as indicated by the reduced levels of ALT, aspartate aminotransferase (AST), alkaline phosphatase (ALP), creatinine, uric acid, creatine kinase in the bloodstream (El-Maaty et al 2014; Hosseini-Vashan et al 2012; Hosseini-Vashan et al 2015). The antioxidant and antiinflammatory activities of curcumin have been attributed to the ameliorating effect of turmeric or curcumin on the liver and kidney damage in broilers under toxicity and stress conditions (Sayrafi et al 2017). Overall, the alleviating effect of turmeric on the physiological condition in heat-stress broilers may consequently restore the growth rate of the chicks during the thermal stress conditions.

Table 2 Effect of turmeric on physiological conditions of heat-stressed broilers.

\begin{tabular}{|c|c|}
\hline References & Findings \\
\hline Bagban et al (2016) & $\begin{array}{l}\text { Turmeric powder }(0.5 \% \text { of diets }) \text { decreased plasma levels of ALT, lactate } \\
\text { dehydrogenase }(\mathrm{LDH}) \text { and uric acid of heat-stressed broilers }\end{array}$ \\
\hline Hosseini-Vashan et al (2012) & $\begin{array}{l}\text { Turmeric powder }(0.4 \% \text { and } 0.8 \%) \text { increased HDL level and decreased total } \\
\text { cholesterol, LDL, LDH, AST, ALT and ALP levels in the plasma of heat-stressed } \\
\text { broilers }\end{array}$ \\
\hline El-Maaty et al (2014) & $\begin{array}{l}\text { Turmeric powder }(0.5 \mathrm{~g} / \mathrm{kg} \text { diet }) \text { decreased plasma levels of AST, ALT, } \\
\text { creatinine, triglycerides, cholesterol, LDL and very-low-density lipoprotein } \\
\text { (VLDL), and an increased HDL level of heat-stressed broilers }\end{array}$ \\
\hline Sadeghi and Moghaddam (2018) & $\begin{array}{l}\text { Turmeric powder ( } 0.5 \% \text { of diets) increased serum concentrations of } \mathrm{T}_{3} \text { and } \mathrm{T}_{4} \text { in } \\
\text { thermal-stressed broilers }\end{array}$ \\
\hline Hosseini-Vashan et al (2015) & $\begin{array}{l}\text { Turmeric rhizome powder }(0.4 \text { and } 0.8 \%) \text { decreased plasma concentrations of } \\
\text { cholesterol, LDL, creatine kinase, AST, ALT and ALP of broiler chickens } \\
\text { exposed to thermal stress }\end{array}$ \\
\hline Swathi et al (2016) & $\begin{array}{l}\text { Turmeric powder ( } 0.4 \% \text { of diets) decreased serum concentration of corticosterone } \\
\text { of broilers exposed to heat stress }\end{array}$ \\
\hline Zeinali et al (2011) & $\begin{array}{l}\text { Turmeric powder }(10 \mathrm{~g} / \mathrm{kg} \text { diets }) \text { increased plasma concentration of } \mathrm{T}_{4} \text { in heat- } \\
\text { stressed broiler chickens }\end{array}$ \\
\hline
\end{tabular}

\section{Effect of turmeric on the immune response of heat- stressed broilers}

The high thermal condition has been associated with the immune depression in broilers (Ohtsu et al 2015; Sugiharto et al 2017b). This may consequently increase the susceptibility of chickens to infectious diseases. Turmeric rhizome powder has previously been demonstrated to improve the heterophil/lymphocyte ratio and immunoglobulin (Ig) G antibody titers against SRBC in broiler study conducted by Akhavan-Salamat and Ghasemi (2016). In line with the latter 
report, Swathi et al (2016) reported that turmeric powder $(0.4 \%$ of diets) increased cell-mediated immune response against phytohaemagglutinin and humoral immune response against Newcastle disease vaccine (NDV) in broilers exposed to heat stress. The increased corticosterone and decreased antioxidant enzyme activities have been associated with the immune depression in broilers maintained under high thermal conditions (Sugiharto et al 2017b). Turmeric was previously reported to prevent the increased corticosterone level in the bloodstream (Swathi et al 2016) while increasing the antioxidant enzyme activities in heat-stressed broilers (ElMaaty et al 2014; Swathi et al 2016). Such conditions may, therefore, alleviate the impairing effect of heat stress on the immune system of broilers. A study by Al-Sultan et al (2003) showed that turmeric increased lymphoid organs (spleen, Bursa of Fabricius, and thymus) weight index, which can, therefore, compensate for the lymphoid organ involution in broiler during thermal stress (Ohtsu et al 2015). Given the crucial role of lymphoid organs in producing and maturing immune cells, the capacity of turmeric in maintaining the development of these organs is therefore essential to keep the chicks healthy during thermal stress conditions.

The disruption of the gut microbial ecosystem and, hence, compromised immune system has been related to heat stress conditions in broiler chickens (Sugiharto et al 2017b). Considering the efficacy of turmeric in decreasing coliform and increasing Lactobacillus counts in the intestine (Samarasinghe et al 2003; Ahlawat et al 2018), gut microbial ecology improvement by turmeric may, therefore, improve the immune status of broiler during heat stress. Yet, the data regarding the ameliorating effect of turmeric on the gut microbial ecology of broilers during heat stress are still scarce. The improvement of immune responses in heat-stressed broilers seemed to also be contributed by the antiinflammatory effect of turmeric and curcumin (Samarasinghe et al 2003; Hewlings and Kalman 2017). Indeed, the antiinflammatory activity of turmeric or curcumin may be responsible for the modulation of the immune cell functions of animals (Kahkhaie et al 2019). Dyslipidemia, which is the enhanced levels of blood cholesterol, triglycerides, LDL, and decreased HDL, has been related to heat stress in broiler chickens exposed to high thermal conditions (Sugiharto et al 2017b). The latter authors as well as study in humans by Madenspacher et al (2010) suggested that dyslipidemia may compromise the immune responses and thus impairs host defense against infectious agents. Since turmeric could avoid broiler from dyslipidemia (Hosseini-Vashan et al 2012), it could, therefore, be reasonable that turmeric improves the immune defense of heat-stressed broilers. A study by Kamel et al (2017) noticed that heat stress implied in decreased numbers of leukocytes and lymphocytes, which are important components of the immune system. Previously, Isroli et al (2017) documented that the administration of decocted turmeric through drinking water increased the numbers of leukocytes and the proportion of lymphocytes in blood as well as the concentration of globulin (precursor of immunoglobulin) in the serum of broilers. On this basis, it could, therefore, be expected that turmeric could compensate for the impairing effect of heat stress on the broiler's immune defenses.

\section{Effect of turmeric on antioxidant status of heat-stressed broilers}

Heat stress has been characterized by the impaired antioxidant system in the body of broilers, such as the reduced activities of glutathione peroxidase (GPx), SOD and catalase, and increased lipid peroxidation (Hosseini-Vashan et al 2016). Indeed the impaired antioxidant enzyme activities may implicate in the increase in free radicals leading to pathophysiological conditions, compromised immune competence, increased lipid peroxidation, and DNA disruption (Devi et al 2000). Feeding turmeric has been reported to ameliorate the impaired antioxidant system in broilers exposed to thermal stress conditions (Table 3). In general, the mechanisms by which turmeric improves the antioxidant system of broiler could be through promoting the activities of antioxidant enzymes as well as alleviating the lipid peroxidation (Akhavan-Salamat and Ghasemi 2016). Curcumin is the active compound in turmeric that serves a crucial role in improving the antioxidant status in broilers. Besides direct scavenging of free radicals, curcumin may increase the synthesis and activate antioxidant enzymes such as GSH, catalase, and SOD and also inhibit ROS-inducing enzymes (Hewlings and Kalman 2017). Note that the increased antioxidant enzyme activities can further implicate lowered lipid peroxidation (Reddy and Lokesh 1994).

\section{Constraints of turmeric in alleviating heat stress effect on broilers}

The potentials of turmeric in ameliorating the negative effect of heat stress in broilers have been described. Different from these positive findings, some investigators reported no effect of dietary supplementation of turmeric on the conditions of broilers when exposed to heat stress. For instance, Hosseini-Vashan et al (2012) administrated turmeric powder at the levels of $0.4 \%$ and $0.8 \%$, but they did not find any substantial impact on body weight gain, feed intake, FCR, and production index of broilers raised under heat stress conditions. In concurrence with this report, Candra and Putri (2020) recently reported that turmeric powder (500 mg per kg body weight of broiler) did not have any influence on the growth rate of broilers maintained in thermal stress conditions. In the case of growth rate, feeding turmeric may not improve the weight gain, but rather improve the carcass traits of broilers as indicated by the lower content of abdominal fat 
(Samarasinghe et al 2003; Sugiharto et al 2011). It is therefore possible that turmeric may increase the deposit of body protein instead of body fat (Samarasinghe et al 2003). The absent effect of turmeric on the physiological condition was also noticed by Zeinali et al (2011), at which administration of turmeric powder $(10 \mathrm{~g} / \mathrm{kg}$ diets $)$ did not affect plasma concentrations of $\mathrm{T}_{3}$, triglycerides, and cholesterol of heatstressed broilers. In respect to immune function, HosseiniVashan et al (2012) did not find any effect of turmeric powder ( $0.4 \%$ and $0.8 \%$ of diets) on antibody response of broilers against SRBC, IgM, IgG and antibody titers against NDV. Some reasons may explain the possible absent effect of feeding turmeric on heat-stressed broilers, one of which is the low solubility, which consequently low bioavailability of turmeric and curcumin for broilers. Hewlings and Kalman (2017) formerly suggested that one of the main problems with turmeric and curcumin is their poor bioavailability due to low solubility, low absorption, rapid metabolism, and elimination. Combining curcumin with other herbs has been suggested to improve the bioavailability of curcumin (Hewlings and Kalman 2017). In agreement with this, Al-Sultan et al (2019) combined turmeric powder and cumin to improve the efficacy of turmeric in alleviating the detrimental effect of heat stress on broilers.

Table 3 Effect of turmeric on the antioxidant status of heat-stressed broilers.

\begin{tabular}{ll}
\hline References & Findings \\
\hline Akhavan-Salamat and Ghasemi (2016) & $\begin{array}{l}\text { Turmeric rhizome powder increased GPx and SOD activities and alleviated the } \\
\text { increased levels of malondialdehyde (MDA) in serum due to heat stress }\end{array}$ \\
Bagban et al (2016) & $\begin{array}{l}\text { Turmeric powder }(0.5 \% \text { of diets) decreased plasma levels of MDA of heat- } \\
\text { stressed broilers }\end{array}$ \\
Hosseini-Vashan et al (2012) & $\begin{array}{l}\text { Turmeric powder }(0.4 \% \text { and } 0.8 \%) \text { increased GPx, decreased thiobarbituric acid } \\
\text { reactive substances (TBARS) levels in plasma and H/L ratio of heat-stressed } \\
\text { broilers }\end{array}$ \\
El-Maaty et al (2014) & $\begin{array}{l}\text { Turmeric powder }(0.5 \mathrm{~g} / \mathrm{kg} \text { diet }) \text { decreased plasma MDA and increased SOD and } \\
\text { GSH levels in heat-stressed broiler }\end{array}$ \\
Turmeric powder $(0.5 \%$ of diets) increased serum levels of SOD but did not affect \\
GPx, catalase, MDA and total antioxidant capacity (TAC) of broiler stressed by \\
high ambient temperature \\
Turmeric rhizome powder ( 0.4 and $0.8 \%)$ increased plasma concentrations of GPx \\
and SOD and decreased TBARS of broilers maintained in heat stress condition
\end{tabular}

\section{Final considerations}

Heat stress is attributed to impaired productive performance and health in broiler chickens. As a part of the nutritional interventions, most of the literature convincingly showed the efficacy of turmeric in alleviating the negative effect of heat stress on broilers in terms of production, physiological conditions, immune responses, and antioxidant system.

\section{Acknowledgments}

The study was supported by Diponegoro University, Semarang, Central Java, Indonesia, contract no. 23323/UN7.6.1/PP/2020.

\section{Conflict of interest}

The author had no conflict of interest.

\section{References}

Adegoke AV, Abimbola MA, Sanwo KA, Egbeyale LT, Abiona JA, Oso AO, Iposu SO (2018) Performance and blood biochemistry profile of broiler chickens fed dietary turmeric (Curcuma longa) powder and cayenne pepper (Capsicum frutescens) powders as antioxidants. Veterinary and Animal Science 6:95-102.

Ahlawat PK, Dalal R, Sonu, Tewatia BS, Panwar VS, Sheoran N (2018) Antimicrobial effect of dietary supplementation of turmeric powder in intestine of broilers. International Journal of Current Microbiology and Applied Sciences 7:2244-2251.

Akhavan-Salamat H, Ghasemi HA (2016) Alleviation of chronic heat stress in broilers by dietary supplementation of betaine and turmeric rhizome powder: dynamics of performance, leukocyte profile, humoral immunity, and antioxidant status. Tropical Animal Health and Production 48:181-188.

Akter J, Hossain MA, Takara K, Islam MZ, Hou DX (2019) Antioxidant activity of different species and varieties of turmeric (Curcuma spp): Isolation of active compounds. Comparative Biochemistry and Physiology Part C: Toxicology \& Pharmacology 215:9-17. 
AL-Sultan SI (2003) The effect of Curcuma longa (tumeric) on overall performance of broiler chickens. International Journal of Poultry Science 2:351-353.

Al-Sultan SI, Abdel-Raheem SM, Abd-Allah SMS, Edris AM (2019) Alleviation of chronic heat stress in broilers by dietary supplementation of novel feed additive combinations. Slovenian Veterinary Research 56(Suppl 22):269-79.

Amr EMM, Ghada OED, Abdel-Azeem SAA, Khaled IEE (2017) Investigation of biochemical and immunological effects of both corticosterone and turmeric powder in broiler chickens. Animal Health Research Journal 5:498-510.

Baghban P, Daneshyar M, Najafi R (2016) Effects of cinnamon (Cinnamomum zeylanicum) and turmeric (Curcuma longa) powders on performance, enzyme activity, and blood parameters of broiler chickens under heat stress. Poultry Science Journal 4:47-53.

Boroumand N, Samarghandian S, Hashemy SI (2018) Immunomodulatory, anti-inflammatory, and antioxidant effects of curcumin. Journal of Herbmed Pharmacology 7:211-219.

Brewer MS (2011) Natural Antioxidants: Sources, Compounds, Mechanisms of Action, and Potential Applications. Comprehensive Reviews in Food Science and Food Safety 10:221-247.

Candra AA, Putri D (2020) Application turmeric as antioxidant for broiler chickens. Journal of Physics: Conference Series 1450 (2020) 012058. doi:10.1088/1742-6596/1450/1/012058

Chakraborty PS, Ali SA, Kaushik S, Ray RK, Yadav RP, Rai MK, Singh D, Bhakat AK, Singh VK, John MD, Das KC, Prasad VG, Nain SS, Singh M, Chandra PK, Singh DK, Rai Y, Singh P, Singh O, Singh AKN, Shah M, Pradhan PK, Bavaskar R, Debata L, Nayak C, Singh V, Singh K (2011) Curcuma longa- A multicentric clinical verification study. Indian Journal of Research in Homeopathy 5:1927.

Devi GS, Prasad MH, Saraswathi I, Raghu D, Rao DN, Reddy PP (2000) Free radicals antioxidant enzymes and lipid peroxidation in different types of leukemias. Clinica Chimica Acta 293:53-62.

El-Maaty A, Hayam MA, Rabie MH, El-Khateeb AY (2014) Response of heat-stressed broiler chicks to dietary supplementation with some commercial herbs. Asian Journal of Animal and Veterinary Advances 9:743-755.

He X, Lu Z, Ma B, Zhang L, Li J, Jiang Y, Zhou G, Gao F (2018) Effects of chronic heat exposure on growth performance, intestinal epithelial histology, appetite- related hormones and genes expression in broilers. Journal of the Science of Food and Agriculture 98:4471-4478.

Hewlings SJ, Kalman DS (2017) Curcumin: a review of its' effects on human health. Foods 6:92.

Hosseini-Vashan SJ, Golian A, Yaghobfar A (2015) Effects of turmeric rhizome powder and source of oil in diet on blood metabolites, immune system and antioxidant status in heat stressed broiler chickens. Journal of Livestock Science and Technologies. 3:13-20.

Hosseini-Vashan SJ, Golian A, Yaghobfar A (2016) Growth, immune, antioxidant, and bone responses of heat stress exposed broilers fed diets supplemented with tomato pomace. International Journal of Biometeorology 60:1183-9112.

Hosseini-Vashan SJ, Golian A, Yaghobfar A, Zarban A, Afzali N, Esmaeilinasab P (2012) Antioxidant status, immune system, blood metabolites and carcass characteristic of broiler chickens fed turmeric rhizome powder under heat stress. African Journal of Biotechnology 11:16118-16125.
Hu X, Guo Y (2008) Corticosterone administration alters small intestinal morphology and function of broiler chickens. AsianAustralasian Journal of Animal Sciences 21:1773-1778.

Huang S, Yang H, Rehman MU, Tong Z (2018) Acute heat stress in broiler chickens and its impact on serum biochemical and electrolyte parameters. Indian Journal of Animal Research 52:683-686.

Isroli I, Yudiarti T, Widiastuti E, Sugiharto S (2017) Effect of decocted turmeric on performance, hematological parameters and carcass traits of broiler chickens. Journal of the Indonesian Tropical Animal Agriculture 42:263-269.

Kahkhaie KR, Mirhosseini A, Aliabadi A, Mohammadi A, Mousavi MJ, Haftcheshmeh SM, Sathyapalan T, Sahebkar A (2019) Curcumin: a modulator of inflammatory signaling pathways in the immune system. Inflammopharmacology. 27:885-900.

Kamel NN, Ahmed AMH, Mehaisen GMK, Mashaly MM, Abass AO (2017) Depression of leukocyte protein synthesis, immune function and growth performance induced by high environmental temperature in broiler chickens. International Journal of Biometeorology 61:1637-1645.

Liu QW, Feng JH, Chao Z, Chen Y, Wei LM, Wang F, Sun RP, Zhang MH (2016) The influences of ambient temperature and crude protein levels on performance and serum biochemical parameters in broilers. Journal of Animal Physiology and Animal Nutrition 100:301-308.

Madenspacher JH, Draper DW, Smoak KA, Li H, Griffiths GL, Suratt BT, Wilson MD, Rudel LL, Fessler MB (2010) Dyslipidemia induces opposing effects on intrapulmonary and extrapulmonary host defense through divergent TLR response phenotypes. Journal of Immunology 185:1660-1669.

Namagirilakshmi S, Selvaraj P, Nanjappan K, Jayachandran S, Visha P (2010) Turmeric (Curcuma longa) as an alternative to in-feed antibiotic on the gut health of broiler chickens. Tamilnadu Journal of Veterinary and Animal Sciences 6:148-150.

Ohtsu H, Yamazaki M, Abe H, Murakami H, Toyomizu M (2015) Heat stress modulates cytokine gene expression in the spleen of broiler chickens. Journal of Poultry Science 52:282-287.

Olfati A, Mojtahedin A, Sadeghi T, Akbari M, Martínez-Pastor F (2018) Comparison of growth performance and immune responses of broiler chicks reared under heat stress, cold stress and thermoneutral conditions. Spanish Journal of Agricultural Research 16:e505.

Papież MA, Kaja M, Gêbarowska A (2008) Age-dependent different action of curcumin in thyroid of rat. Folia Histochemica et Cytobiologica 46:205-211.

Rajput N, Muhammad N, Yan R, Zhong X, Wang T (2013) Effect of dietary supplementation of curcumin on growth performance, intestinal morphology and nutrients utilization of broiler chicks. Journal of Poultry Science 50:44-52.

Reddy AC, Lokesh BR (1994) Effect of dietary turmeric (Curcuma longa) on iron-induced lipid peroxidation in the rat liver. Food and Chemical Toxicology 32:279-283.

Sadeghi AA, Moghaddam M (2018) The effects of turmeric, cinnamon, ginger and garlic powder nutrition on antioxidant enzymes' status and hormones involved in energy metabolism of broilers during heat stress. Iranian Journal of Applied Animal Science 8:125-130.

Samarasinghe K, Wenk C, Silva KFST, Gunasekera JMDM (2003) Turmeric (Curcuma longa) root powder and mannanoligosaccharides as alternatives to antibiotics in broiler chicken diets. AsianAustralasian Journal of Animal Sciences 16:1495-1500. 
Santos RR, Awati A, Roubos-van den Hil PJ, van Kempen TATG, Tersteeg-Zijderveld MHG, Koolmees PA, Smits C, Fink-Gremmels J (2019) Effects of a feed additive blend on broilers challenged with heat stress. Avian Pathology 48:582-601.

Sayrafi R, Hosseini SM, Ahmadi MA (2017) The protective effects of nanocurcumin on liver toxicity induced by salinomycin in broiler chickens. Revue de Médecine Vétérinaire 168:136-142.

Shi D, Bai L, Qu Q, Zhou S, Yang M, Guo S, Li Q, Liu C (2019) Impact of gut microbiota structure in heat-stressed broilers. Poultry Science 98:2405-2413.

Sugiharto S, Isroli I, Widiastuti E, Prabowo N (2011) Effect of turmeric extract on blood parameters, feed efficiency and abdominal fat content in broilers. Journal of the Indonesian Tropical Animal Agriculture 36:21-26.

Sugiharto S, Yudiarti T, Isroli I, Widiastuti E, Putra FD (2017a) Effect of dietary supplementation with Rhizopus oryzae or Chrysonilia crassa on growth performance, blood profile, intestinal microbial population, and carcass traits in broilers exposed to heat stress. Archives Animal Breeding 60:347-356.

Sugiharto S, Yudiarti T, Isroli I, Widiastuti E, Kusumanti E (2017b) Dietary supplementation of probiotics in poultry exposed to heat stress - a review. Annals of Animal Science 17:591-604.

Sugiharto S, Yudiarti T, Isroli I, Widiastuti E, Wahyuni HI, Sartono TA (2019) Fermented feed as a potential source of natural antioxidants for broiler chickens - a mini review. Agriculturae Conspectus Scientificus 84:313-318.
Swathi B, Gupta PSP, Nagalakshmi D, Raju MVLN (2016) Efficacy of turmeric (Curcuma longa) as antioxidant in combating heat stress in broiler chicken. Indian Journal of Poultry Science 51:48-53.

Tanvir EM, Hossen MS, Hossain MF, Afroz R, Gan SH, Khalil MI, Karim N (2017) Antioxidant properties of popular turmeric (Curcuma longa) varieties from Bangladesh. Journal of Food Quality 2017:8471785.

Xie Z, Shen G, Wang Y, Wu C (2019) Curcumin supplementation regulates lipid metabolism in broiler chickens. Poultry Science 98:422-429.

Xu Y, Lai X, Li Z, Zhang X, Luo Q (2018) Effect of chronic heat stress on some physiological and immunological parameters in different breed of broilers. Poultry Science 97:4073-4082.

Zaytsoff SJM, Brown CLJ, Montina T, Metz GAS, Abbott DW, Uwiera RRE, Inglis GD (2019) Corticosterone-mediated physiological stress modulates hepatic lipid metabolism, metabolite profiles, and systemic responses in chickens. Scientific Reports 9:19225.

Zeinali A, Kermanshahi H, Riasi A, Farhangfar H, Sarir H, Ziaie H (2011) Effect of sodium selenite and turmeric powder on thyroid hormones and plasma lipids of broiler chickens under heat stress condition. Global Veterinaria 6:237-240.

Zhang JF, Bai KW, Su WP, Wang AA, Zhang LL, Huang KH, Wang $\mathrm{T}$ (2019) Curcumin attenuates heat-stress-induced oxidant damage by simultaneous activation of GSH-related antioxidant enzymes and Nrf2-mediated phase II detoxifying enzyme systems in broiler chickens. Poultry Science 97:1209-1219. 